\title{
To Evaluate the Prevalence and Risk Factors of Dry Eye Disease in a Hospital based Population in Central India
}

Dr. Sonalee Mittal", Dr. Dinesh Mittal

Drishti the Vision Eye Hospital Vijaynagar Indore, DF 63, Sceme No 74c, Opp OM Gurudev Complex, Vijay Nagar, Indore, Madhya Pradesh, India

DOI: $10.36347 /$ sjams.2020.v08i06.014

| Received: 03.06.2020 | Accepted: 15.06.2020 | Published: 18.06.2020

*Corresponding author: Dr. Sonalee Mittal

Aim: The Aim of this Study was to find out the Prevalence of Dry Eye and Evaluate Personal and Environmental Risk Factors attributable to Dry Eye in a Hospital-based population of Central India. Materials and Methods: In this CrossSectional Study, 1450 patients above 20 years of age were screened for Dry Eye. Ocular Surface Disease Index Questionnaire (OSDI), Schirmer's Test, Tear Film Breakup Time (TBUT) and Fluorescein and Lissamine Vital Staining were used to diagnose Dry Eye. Patient Demographics including Age, Sex, Smoking, Occupation and Working Environment were recorded. Correlation of Dry Eye symptoms with Signs and TBUT and Schirmer's tests was assessed. An OSDI score of 22 or more with a TBUT of less than $10 \mathrm{~s}$ or Schirmer's test reading of less than 10 $\mathrm{mm}$ was considered Diagnostic of Definite DED. Descriptive and analytical statistics were performed. In all comparisons, P value less than 0.05 was considered to be statistically significant. Results: Dry eye disease prevalence was $30 \%$ (435 patients) in the 1450 patients. DED was significantly more prevalent in patients 20 to 40 years old. An OSDI score more than 22 was found in 50\% (725 patients), TBUT less than $10 \mathrm{~s}$ in $44 \%$ (638 patients), and Schirmer's test score less than $10 \mathrm{~mm}$ in $24 \%$ (348 patients). DED symptoms are significantly associated with Meibomian Gland Dysfunction, Previous Refractive Surgery, Previous Cataract Surgery, Ocular Allergy, Pterygium and Diabetes. Conclusion: The prevalence of DED is 30\%. Video Display Terminals use, Smoking, and Contact Lens use were associated with increased risk of developing DED. Dry eye is a leading cause of ocular discomfort in OPD patients. Excessive exposure to wind, sunlight, high temperature, and air pollution was significantly related to Dry Eyes. There was a significant correlation between patient's history, symptoms, dry eye signs and objective tests for tear film. The rural people and those with outdoor occupation are more exposed to extraneous influences of environmental factors in tropical climate. These factors affect the tear film and ocular surface causing the Dry Eye Syndrome.

Keywords: Dry Eye Disease, India, Visual Display Terminal.

Copyright @ 2020: This is an open-access article distributed under the terms of the Creative Commons Attribution license which permits unrestricted use, distribution, and reproduction in any medium for non-commercial use (NonCommercial, or CC-BY-NC) provided the original author and source are credited.

\section{INTRODUCTION}

Primary Objective of the study was to analyze the Prevalence of Symptomatic DED based on the OSDI Questionnaire and to Analyze the associated Risk Factors. The Secondary objective was to assess the tear film stability and secretion in patients with symptoms of DED.

Dry Eye Disease (DED), also known as Dry Eye Syndrome (DES) or Keratoconjunctivitis Sicca $(\mathrm{KCS})$, is characterized by Ocular Irritation and Visual Disturbance resulting from Alterations of the Tear Film and Ocular Surface. The effects of DED can vary from
Minor inconvenience to rare Sight-threatening complications. Although the diagnosis of DED traditionally was focused on inadequate secretion or aqueous tear deficiency, the tear film is a complex and delicately balanced unit dependent on the normal function of several distinct components.

The term 'Dry Eye' evolved until 1995 when Dry Eye was defined as: Dry eye 1 is a disorder of the tear film due to tear deficiency or excessive tear evaporation, which causes damage to interpalpebral ocular surface and is associated with symptoms of discomfort. 


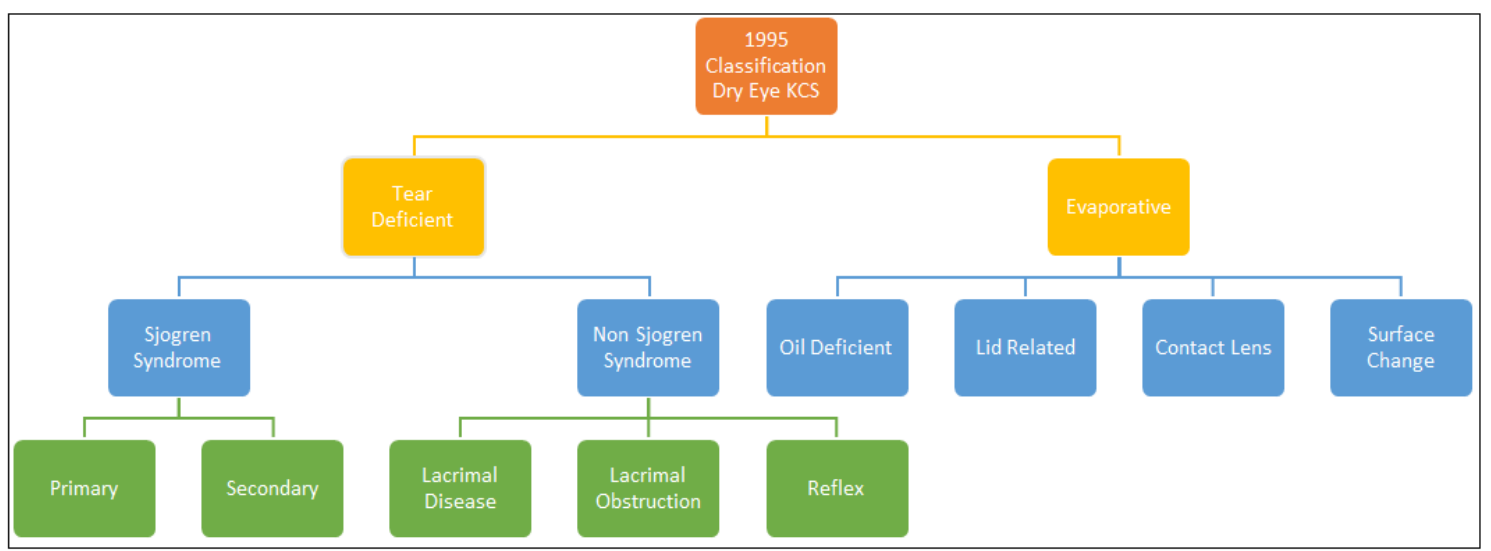

Chart-1: Dry Eye Definition 1995

At this stage Dry Eye was termed a "Disorder" of the Tear Film with signs and symptoms attributed to tear deficiency or excessive evaporation.

In 2007, the International Dry Eye Workshop2 coined a New Definition for Dry Eye as a Multifactorial disease of the tears and ocular surface that results in symptoms of discomfort, visual disturbance, and tear film instability with potential damage to the ocular surface. It is accompanied by increased osmolarity of the tear film and inflammation of the ocular surface.

The 1995 definition of Dry Eye identified Discomfort as the principal symptomatic response associated with Dry Eye, and the 2007 definition expanded the concept of Symptoms to include Visual Disturbance.

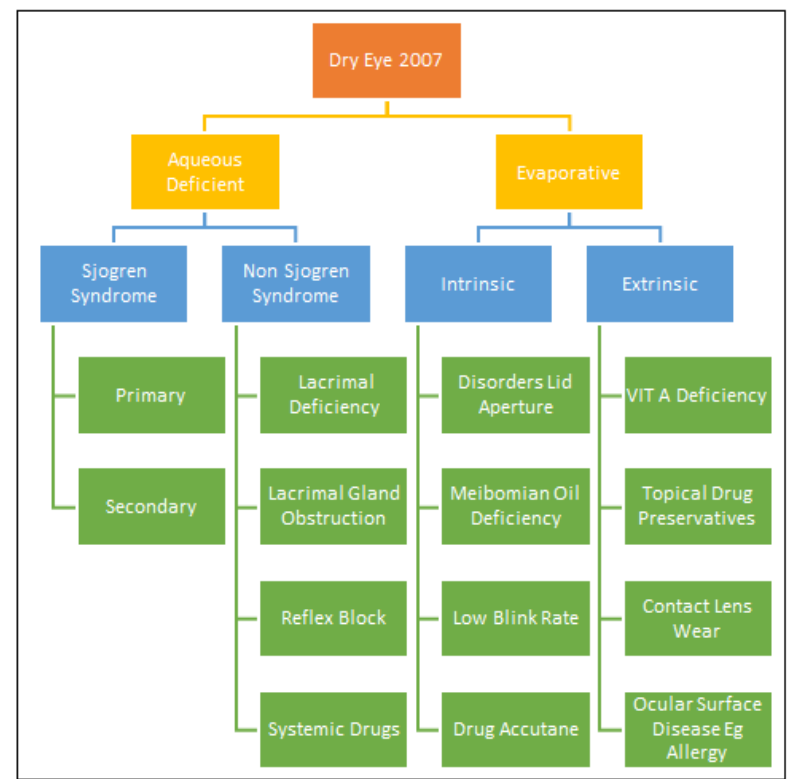

Chart-2: Dry Eye Disease Definition 2007

The 2017 International Dry Eye Workshop (DEWS II)3 Report updated the Definition of Dry Eye as follows: "Dry eye is a Multifactorial Disease of the Ocular Surface characterized by a Loss of Homeostasis of the Tear Film, and accompanied by ocular symptoms, in which Tear Film instability and Hyperosmolarity, Ocular Surface Inflammation and Damage, and Neurosensory Abnormalities play etiological roles." The new definition emphasizes the Multifactorial nature of DED, where Loss of Homeostasis of the Tear Film is the central pathophysiological concept. It also recognizes the role of neurosensory abnormalities in the development of DED.

\section{Diagnosis of Dry Eye}

Making an accurate clinical diagnosis of Dry Eye Disease is not always straightforward, as signs and symptoms of DED are often poorly correlated. Traditionally, combinations of questionnaires, diagnostic tests and slit lamp examination have been used to assess symptoms and clinical signs. The combination of history and examination is imperative because some patients have significant symptoms but few findings, whereas others have significant clinical findings with only mild symptoms. Symptoms and at least one positive result of the markers of homeostasis listed below should constitute the diagnosis of DED.

If DED is suspected, a positive result to a Screening Questionnaire such as the 5-item Dry Eye Questionnaire (DEQ-5) or the Ocular Surface Disease Index (OSDI) should trigger further evaluation, with Tear Break-Up Time ${ }^{4}$ (non-invasive methods preferred), Tear Film Osmolarity determination, and Ocular Surface Staining (that includes the Cornea and Conjunctiva ) with Fluorescein and Lissamine Green. Identification of a disruption in tear film homeostasis with these tests, allows a diagnosis of Dry Eye to be made. This standardized approach will facilitate improved epidemiological DED research and therapeutic regulatory approvals in future. Other tests, such as Meibography, Lipid Layer Interferometry, Evaporation and Tear Volume Measurements can help clarify where the individual with DED falls on the Evaporative and Aqueous Deficient DED subtype classification spectrum and promote the selection of appropriate therapeutic interventions. 


\section{PATIENTS AND METHODS}

This prospective, cross-sectional, observational, hospital-based study examined 1450 consecutive patients presenting for eye examination to a General Ophthalmology Hospital in Indore City between January 2017 and August 2019. Younger patients, <20 years old, were not included in the study, because of their inadequate cooperation for Schirmer's test and TBUT. Inclusion criteria were as follows: patients above 20 years of age presenting with various ophthalmic complaints such as irritation, discomfort, dryness, presence of foreign body sensation, gritty sensation, burning sensation, and light sensitivity. All patients underwent a through history check by an ophthalmologist. The active complaints were recorded. Complementary use of a validated symptom questionnaire is helpful, both to screen for DED as well as to follow-up treatment effect. The OSDI Questionnaire $^{5}$ is a useful tool for DED evaluation because of its simplicity and ease of use, which prompted us to use it after being translated in Hindi. It is a 12- Item Scoring Survey, in which the patient rates his or her own ocular symptoms induced by environmental factors over the preceding 2-4 weeks. Answers are scored on a scale from 0 to 4 ; the total score can range from 0 to 100 , with higher scores representing greater disability. The OSDI has an overall score and three subscale scores [Ocular Symptoms (three items), Vision-Related Function (six items), and Environmental Triggers (three items)]. Each OSDI item is scored on a scale ranging from 0 to 4 points, where 0 indicates none of the time and 4 indicates all of the time.

The final score was calculated by multiplying the sum of all the scores by 25 and then dividing the total by the number of questions answered. On the basis of their OSDI scores, patients can be categorized as having a Normal Ocular Surface (0-12 points) or as having Mild (13-22 points), Moderate (23-32 points), or Severe (33-100 points) Ocular Surface Disease.

Table-1: OSDI Questionnaire Scoring Ocular Surface Disease Index (OSDI)

\begin{tabular}{|l|l|}
\hline Ocular Surface & Final Scores \\
\hline Normal Ocular Surface & $0-12$ points \\
\hline Mild Ocular Surface Disease & $13-22$ points \\
\hline Moderate Ocular Surface Disease & $23-32$ points \\
\hline Severe Ocular Surface Disease & $33-100$ points \\
\hline
\end{tabular}

Table-2: OSDI Questionnaire

\begin{tabular}{|c|c|c|c|c|c|}
\hline $\begin{array}{l}\text { OSDI नेत्र की सतह का रोग सूचक } \\
\text { Hindi Translation }\end{array}$ & $\begin{array}{l}\text { All Time } \\
\text { पूरा समय }\end{array}$ & $\begin{array}{l}\text { Most Time } \\
\text { सबसे अधिक } \\
\text { समय }\end{array}$ & $\begin{array}{l}\text { Half Time } \\
\text { आधा } \\
\text { समय }\end{array}$ & $\begin{array}{l}\text { Some Time } \\
\text { कुछ समय }\end{array}$ & $\begin{array}{l}\text { None Time } \\
\text { कभी नहीँ }\end{array}$ \\
\hline \multicolumn{6}{|c|}{$\begin{array}{l}\text { Have you experienced any of the following during the last week? } \\
\text { क्या आपने पिछले सप्ताह के दौरान निम्नलिखित में से किसी का अनुभव किया है? }\end{array}$} \\
\hline \multicolumn{6}{|c|}{\begin{tabular}{l|l|l|}
1 Eyes that is sensitive to light? & \\
1 आंखें जो प्रकाश के प्रति संवेदनशील हैं? &
\end{tabular}} \\
\hline \multicolumn{6}{|l|}{$\begin{array}{l}2 \text { Eyes that feels gritty? } \\
2 \text { आँखें जो किरकिरा महसूस करती हैं? }\end{array}$} \\
\hline \multicolumn{6}{|l|}{$\begin{array}{l}3 \text { Painful or sore eyes दर्दनाक या कष्टप्रद } \\
\text { आँखें? }\end{array}$} \\
\hline \multicolumn{6}{|l|}{4 Blurred vision? 4 धुंधली दृष्टि? } \\
\hline \multicolumn{6}{|c|}{\begin{tabular}{|l|l|l|l|l|}
5 Poor visions? 5 खराब हृष्टि? & & & & \\
\end{tabular}} \\
\hline \multicolumn{6}{|c|}{$\begin{array}{l}\text { Have problems with your eyes limited you in performing any of following during the last week? } \\
\text { पिछले सप्ताह के दौरान निम्नलिखित में से कोई भी प्रदर्शन करने में आपकी आँखों की समस्याओं ने आपको सीमित कर दिया है? }\end{array}$} \\
\hline \multicolumn{6}{|c|}{ 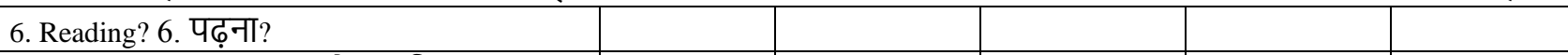 } \\
\hline \multicolumn{6}{|l|}{ 7. Driving at night? 7. रात में ड्राइविंग? } \\
\hline \multicolumn{6}{|l|}{$\begin{array}{l}\text { 8. Working with a computer or smart phone? } \\
\text { 8. कंप्यूटर या स्मार्ट फोन के साथ काम करना? }\end{array}$} \\
\hline \multicolumn{6}{|l|}{ 9. Watching TV? 9. टीवी देखना? } \\
\hline \multicolumn{6}{|c|}{$\begin{array}{l}\text { Have your eyes felt uncomfortable in any of the following situations during the last week? क्या आपकी आँखें पिछले सप्ताह के } \\
\text { दौरान निम्नलिखित में से किसी भी स्थिति में असहज महसूस कर रही हैं? }\end{array}$} \\
\hline \multicolumn{6}{|c|}{ 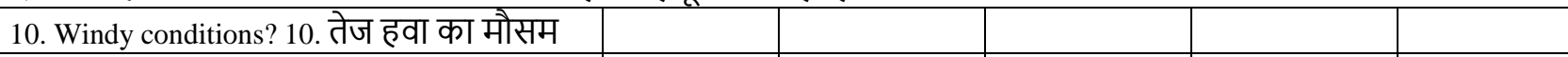 } \\
\hline \multicolumn{6}{|l|}{$\begin{array}{l}\text { 11. Places or areas with low humidity (very } \\
\text { dry)? } \\
\text { 11. कम आर्द्रता (बहुत शुष्क) वाले स्थान या } \\
\text { क्षेत्र? }\end{array}$} \\
\hline $\begin{array}{l}\text { 12. Areas that are air conditioned? } \\
\text { 12. वे क्षेत्र जो वातानुकूलित हैं? }\end{array}$ & & & & & \\
\hline
\end{tabular}




\section{Ocular Examination}

A Complete Ocular Examination was carried out. The lids were examined for the presence of any anatomical abnormalities interfering with normal spread of tear film. Slit Lamp Biomicroscopy was performed, and the presence of mucus strands in the tear film and corneal filaments was noted. Lid margins were examined for irregularity or thickening.
Recommended sequence of Diagnostic Tests for Dry Eye Patients is

1. Fluorescein Strip with small non preserved saline drop:

a. Measure Tear Break-Up Time

b. Look for Staining of the Ocular Surface

2. Lissamine Green Strip with small non preserved saline drop: Look for Conjunctival Staining

3. Place Schirmer strips in both eyes (no anesthesia): measure wetness after 5 minutes

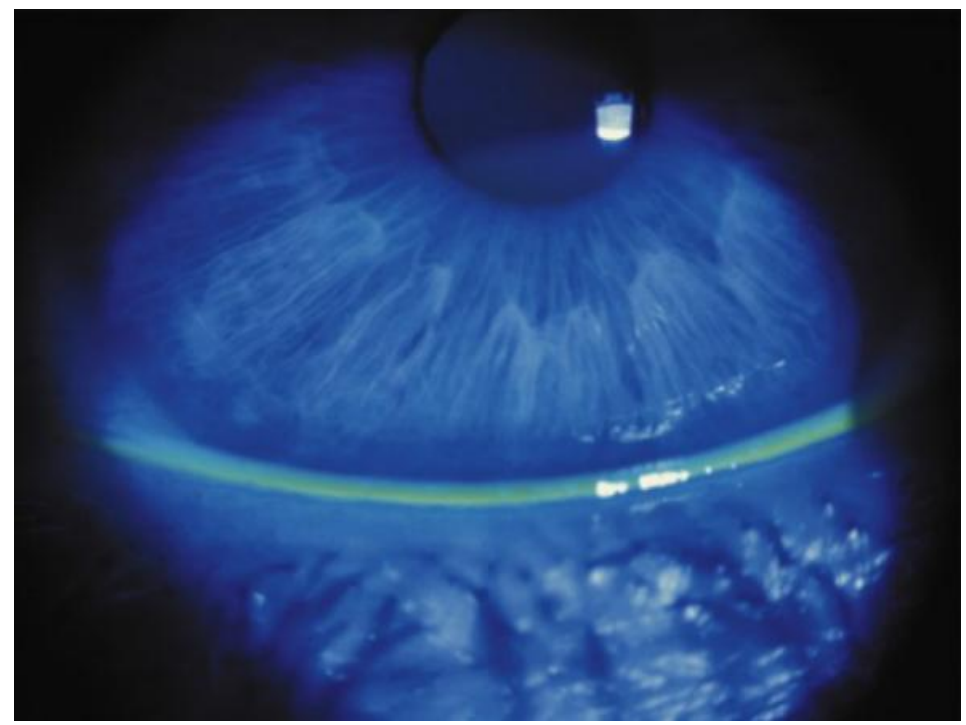

Fig-1: Fluorescein-Stained Marginal Tear Strip

Examination of the Inferior Marginal Tear Strip TMH (Tear Meniscus Height) can yield information about the volume of tears present on the ocular surface. The Tear Strip is a line of tears just above the lower lid. It is normally about $0.5 \mathrm{~mm}$ in width and has a concave upper aspect. When this strip is thin or discontinuous, it is evidence of deficient aqueous tear volume. The tear strip is better visualized by Fluorescein Staining.

Another feature frequently seen in dry eye is increased debris in the tear film. Bits of mucus, fragments of sheets of sloughed epithelial cells, and other foreign material trapped in the tear film are suggestive of delayed tear clearance seen in dry eye.

\section{Tear Break up Time (TBUT)}

TBUT is a sign of Dry Eye. To measure tear TBUT, the patient is asked to blink, which evenly distributes the tear film across the cornea. As the tear film thins, dry spots (1) develop on the surface of the cornea. The time for this to occur is measured. Tear BUTs of 10 seconds or less are considered abnormal.

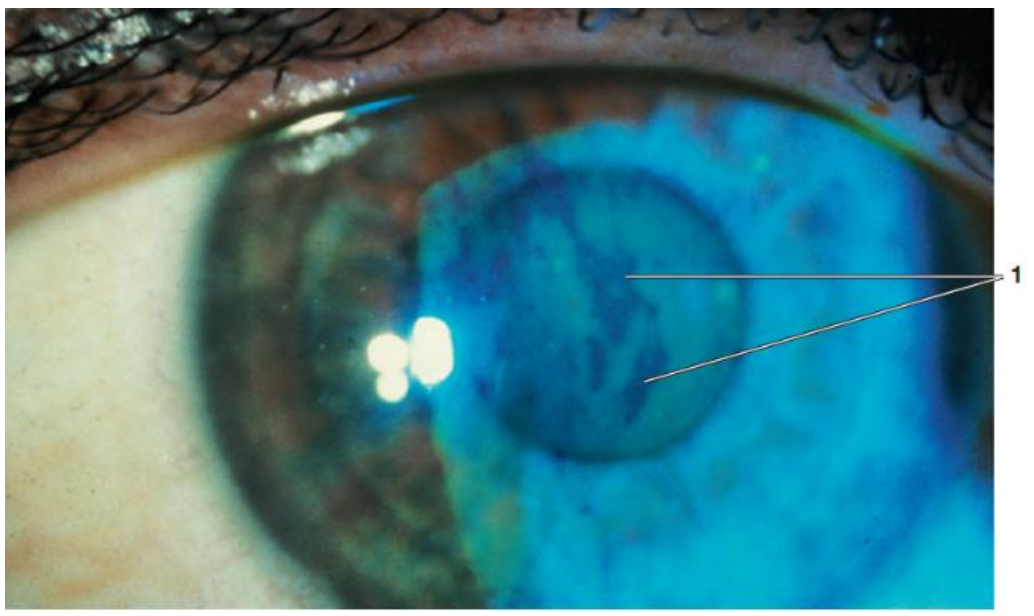

Fig-2: TBUT 
Fluorescein was applied to the ocular surface. The patient was asked to blink a few times before examination. Slit Lamp Biomicroscopy with a Cobalt Blue Filter was used to investigate the tear film layer, and the interval from the last blink to the appearance of the first random dry spot on the cornea was noted. The test was repeated thrice and the mean value was calculated. Value of $<10 \mathrm{~s}$ was considered as indicative of Tear Film Instability.

\section{Schirmer's Test}

Whatman Filter Paper No 41 (measuring $5 \mathrm{~mm}$ $\times 35 \mathrm{~mm}$ ) was placed in the lower fornix at the lateral one-third of the lower lid margin. The extent of wetting of the strip was measured after $5 \mathrm{~min}$. Less than $10 \mathrm{~mm}$ of wetting was considered as Abnormal and Less than $5.5 \mathrm{~mm}$ of wetting was diagnostic of Severe Dry Eye. Schirmer's test was done without anesthesia. To avoid the influence of conjunctiva-corneal staining on the Schirmer test, it was carried out at an interval of $10 \mathrm{~min}$ after the TBUT test. Schirmer's test without Anesthesia measures Basal and Reflex Tear Secretion.

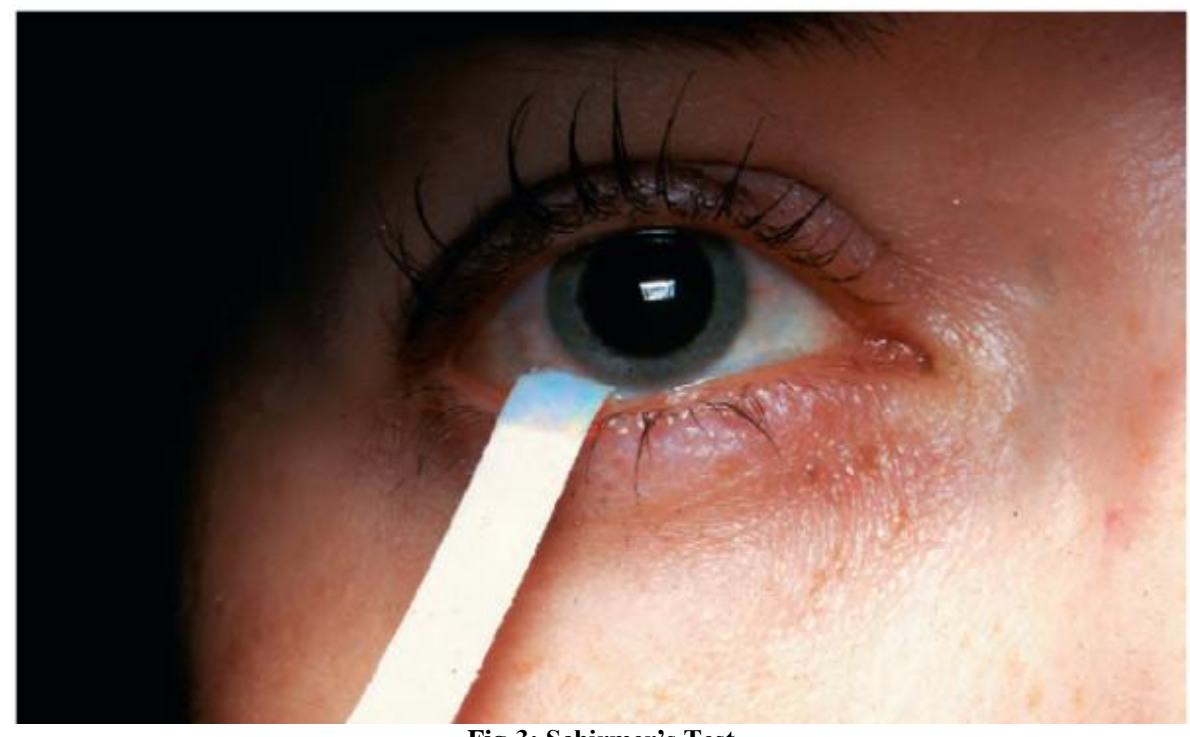

Fig-3: Schirmer's Test

Rose Bengal Stains conjunctival and corneal epithelial cells that have a disruption to the overlying mucin layer or damage to the epithelial cell wall.

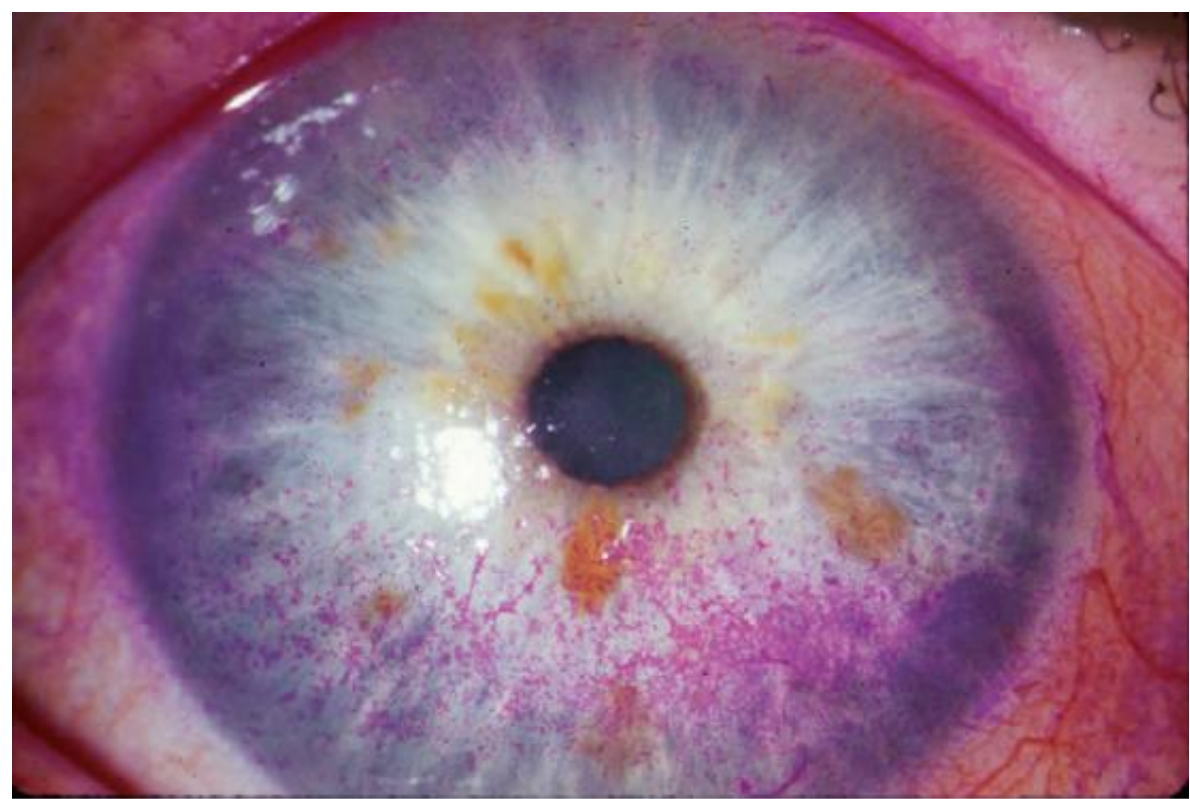

Fig-4: Rose Bengal Stain 


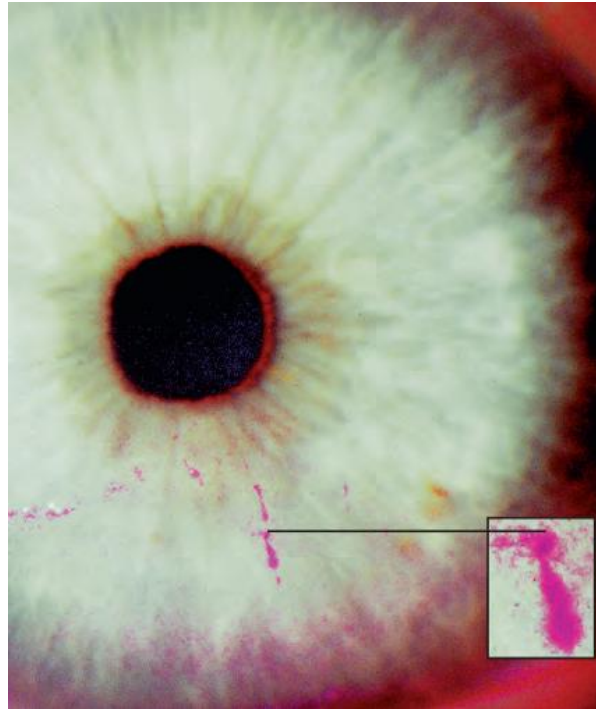

Fig-5: Rose Bengal Stains Mucous Filaments

Rose Bengal epithelial staining is more difficult to visualize than fluorescein; however, its utility lies in its greater sensitivity for staining the conjunctiva. Rose Bengal staining is enhanced when visualized with red-free light. Unfortunately, it is not tolerated as well as fluorescein and frequently causes irritation and reflex tearing. Rose Bengal stains devitalized epithelial cells as well as epithelial cells that lack a healthy layer of protective mucin coating. In addition to epithelial cells, Rose Bengal also stains mucous filaments (inset). Mucous does not stain well with fluorescein.
Lissamine Green B is similar to Rose Bengal in its staining characteristics, and produces much less irritation after topical administration than Rose Bengal. Several studies have demonstrated the staining pattern with lissamine green to be identical to that of rose Bengal, and it is now commonly used as an alternative.

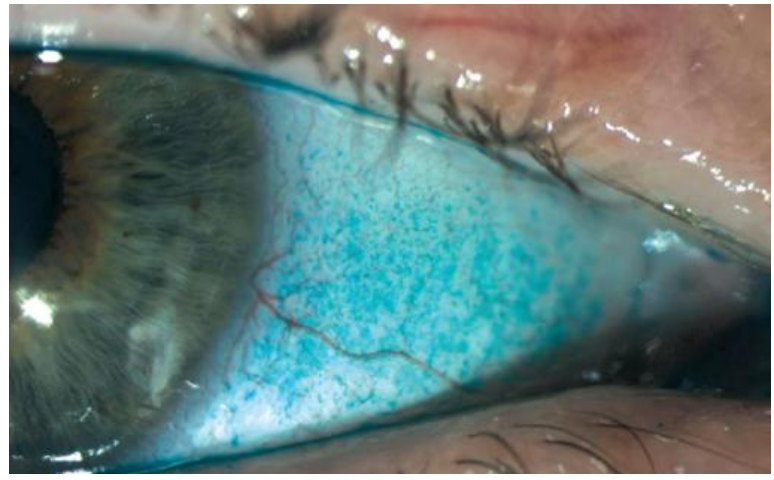

Fig-6: Lissamine Green Staining

Typically the conjunctiva stains to a greater extent than the cornea. Vital dye staining is one of the most useful diagnostic tools for assessing the health of the ocular surface. For consistent recording of staining severity of the ocular surface, there are various grading systems including the Van Bijsterveld System and the Oxford Scheme. Corneal and conjunctival staining have been shown to be important markers of disease severity in DED.

Table-3: Grading Scales for Ocular Surface Staining6

\begin{tabular}{|l|l|l|l|}
\hline \multicolumn{4}{|c|}{ Grading Scales for Ocular Surface Staining } \\
\hline Scale & Cornea & Conjunctiva & Features \\
\hline Van & 1: few separated spots & Nasal and temporal zones: & Focus of Sjogren Syndrome \\
Bijsterveld & 2: many separated spots & 1: few separated spots & Out of 9 \\
System & 3: confluent spots & 2: many separated spots & \\
& & 3: confluent spots & \\
\hline Oxford & Fluorescein, Lissamine Or Rose Bengal can be used; 0 to V & Dots increase on a log scale \\
Staining & grade dependent on intensity of punctate staining displayed & between grades \\
Score & pictorially across a combination of the cornea and conjunctiva. & \\
\hline
\end{tabular}

\section{Management of DED}

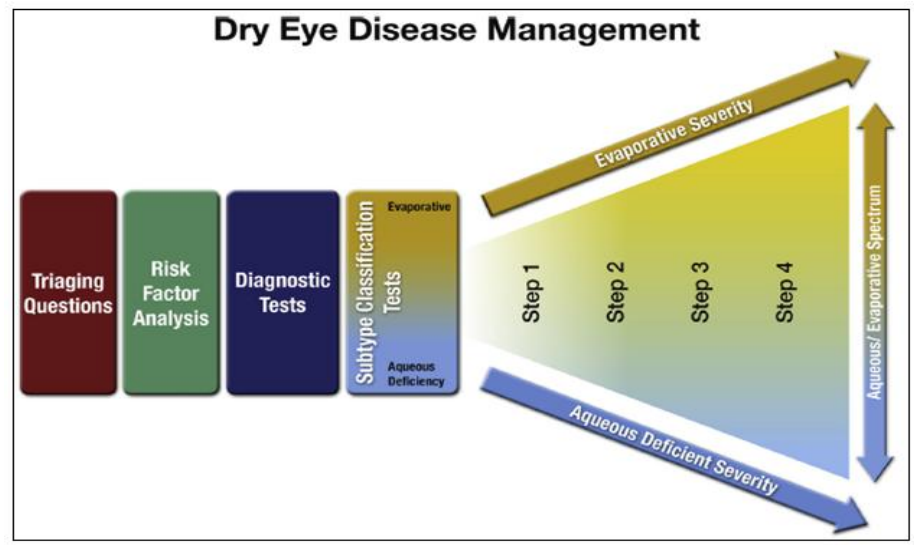

Chart-3: Dry Eye Disease Diagnosis and Management 2017 
Staged Management and Treatment Recommendations for Dry Eye Disease

STEP 1:

- Education regarding the condition, its management, treatment and prognosis

- Modification of local environment

- Education regarding dietary modification (including oral essential fatty acid supplementation)

- Identification and modification/elimination of offending systemic and topical medications

- Ocular lubricants of various types

- Lid hygiene and warm compresses of various types

STEP 2: If above options are inadequate consider:

- Non-preserved ocular lubricants to minimize preservative-induced toxicity

- Tea Tree Oil treatment for Demodex (if present)

- Tear conservation \& Punctal Occlusion

- Moisture chamber spectacles/goggles

- Overnight treatments (such as ointment or moisture chamber devices)

- In-office, physical heating and expression of the Meibomian Glands (including deviceassisted therapies, such as LipiFlow)

- In-office intense Pulsed Light Therapy for MGD

- Prescription drugs to manage DED

- Topical Antibiotic or Antibiotic/Steroid combination applied to lid margins for blepharitis

- $\quad$ Topical Corticosteroid (limited-duration)
- Topical Secretagogues

- Topical Non-Glucocorticoid Immunomodulatory Drugs (Cyclosporine)

- Topical Lymphocyte Function-Associated Antigen 1 (LFA-1) Antagonist drugs (Lifitegrast)

- Oral Macrolide or Tetracycline Antibiotics

STEP 3: If above options are inadequate consider:

- Oral Secretagogues

- Autologous/Allogeneic Serum Eye Drops

- Therapeutic Contact Lens options

- $\quad$ Soft Bandage Lenses \& Rigid Scleral Lenses

STEP 4: If above options are inadequate consider:

- Topical Corticosteroid for longer duration

- Amniotic Membrane Grafts

- Surgical Punctal Occlusion

- Other Surgical Approaches (eg Tarsorrhaphy, Salivary Gland Transplantation)

In General, Management of Dry Eye begins with Conventional, Low-Risk and commonly available therapies such as over-the-counter lubricants for early stage disease, and progress to more advanced therapies for more severe forms of DED.

\section{RESULTS}

Dry eye disease prevalence was $30 \%$ (435 patients) in the 1450 patients. DED was significantly more prevalent in patients 20 years or older and in females.

Table-4: Prevalence of Dry Eye

\begin{tabular}{|l|l|l|}
\hline \multicolumn{2}{|l|}{ Prevalence of Dry Eye } \\
\hline Patients having Dry Eye & Patients does not Have Dry Eye & Total Patients \\
\hline 435 & 1015 & 1450 \\
\hline
\end{tabular}

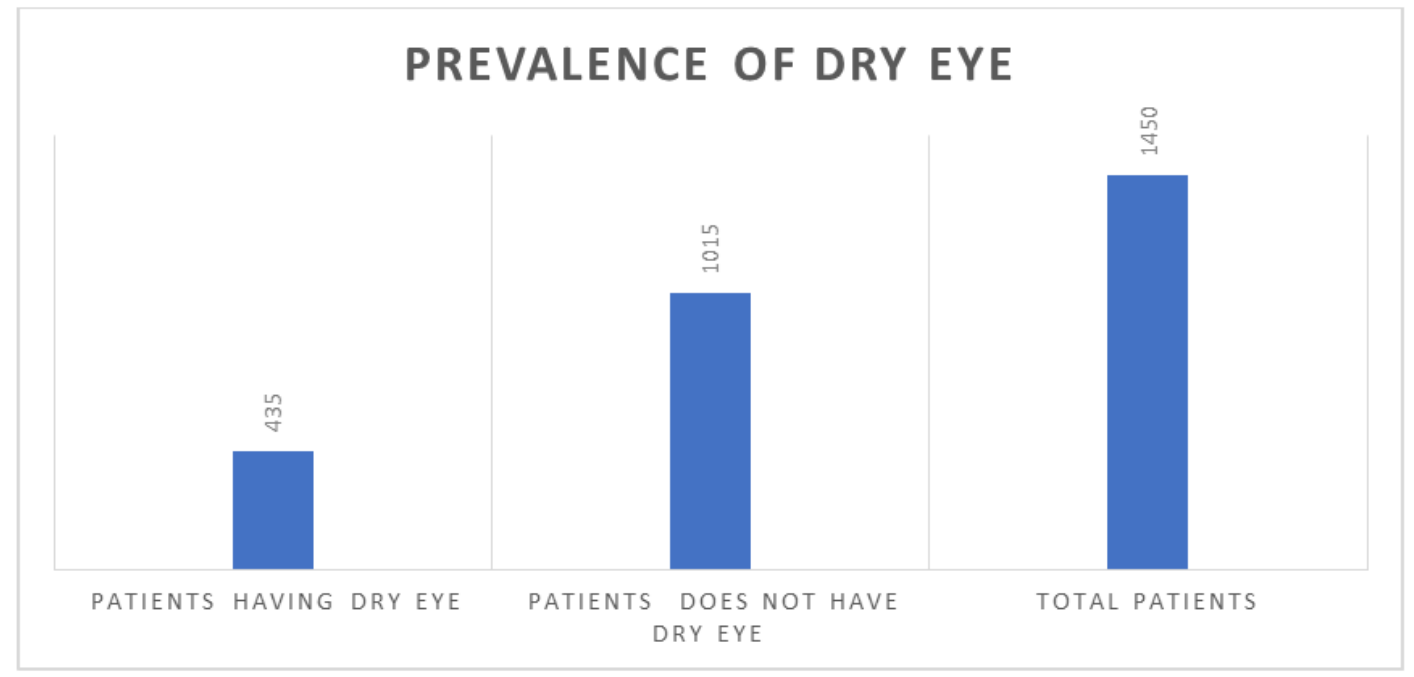

Chart-4: Prevalence of Dry Eye 
Table-5: Age and Sex Distribution of Patients

\begin{tabular}{|l|l|l|l|}
\hline \multicolumn{4}{|c|}{ Age and sex distribution of 1450 patients } \\
\hline Age Group (Years) & Male & Female & Total \\
\hline 20 to 40 & 296 & 234 & 530 \\
\hline 40 to 60 & 234 & 221 & 455 \\
\hline Above 60 & 220 & 245 & 465 \\
\hline total & 750 & 700 & 1450 \\
\hline
\end{tabular}

\section{Age and Sex Distribution of Patients}

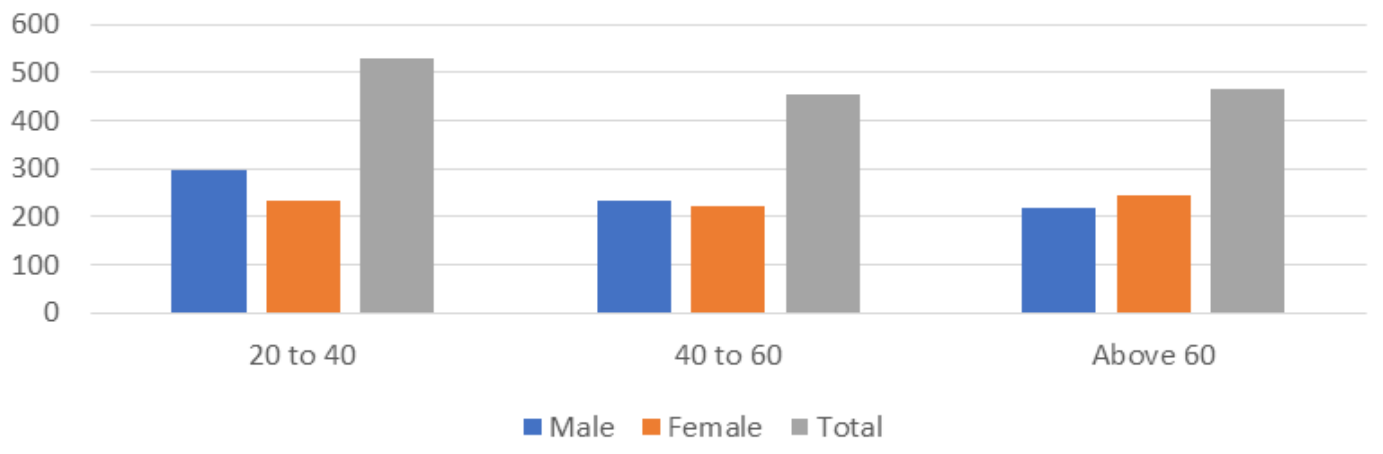

Chart-5: Age and Sex Distribution of Patients

Table-6: Profile of OSDI, TBUT and Schirmer's Test Profile of OSDI, TBUT and Schirmer's Test

\begin{tabular}{|l|l|}
\hline Procedure Done & Patients \\
\hline Patients Having OSDI $>22$ & 725 Patients \\
\hline Patients having TBUT $<10 \mathrm{sec}$ & 638 Patients \\
\hline Patients having Schirmer's Test $<10 \mathrm{~mm}$ & 348 patients \\
\hline
\end{tabular}

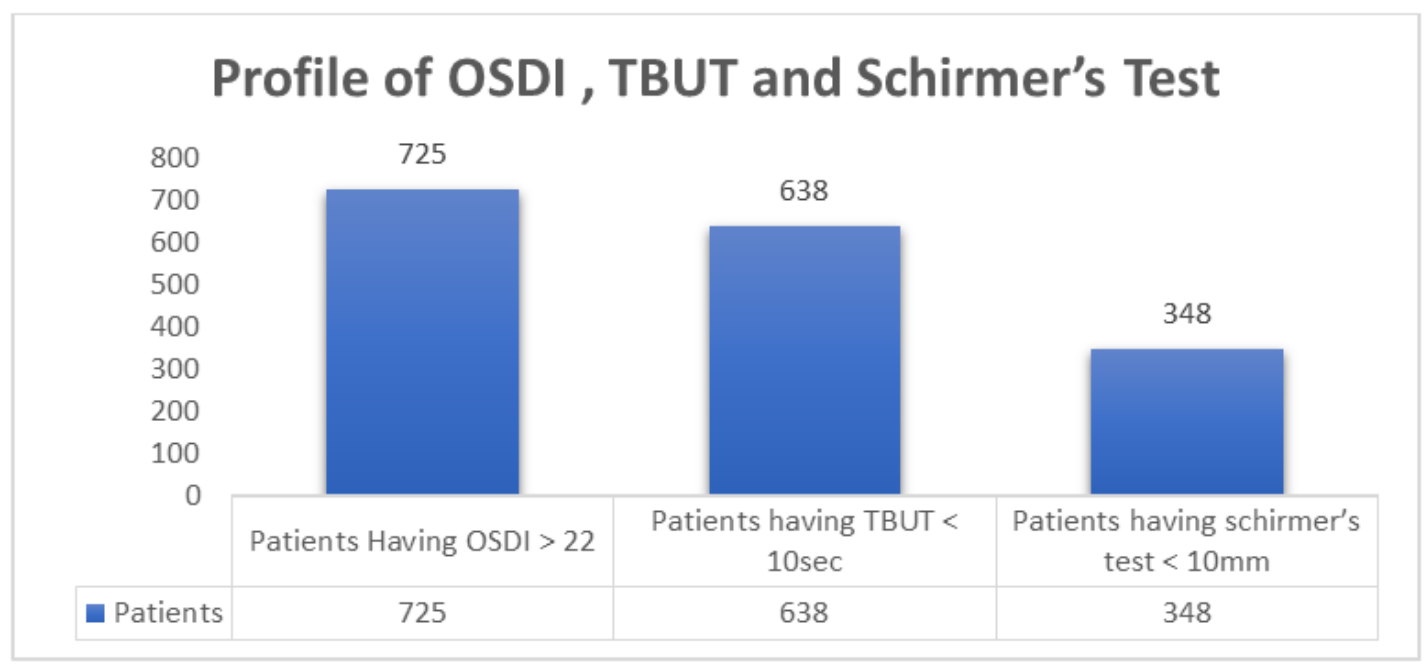

Chart-6: Profile of OSDI, TBUT and Schirmer's Test

Table-7: Severity of Dry Eye

\begin{tabular}{|l|l|l|}
\hline \multicolumn{3}{|l|}{ Severity of Dry Eye } \\
\hline Mild Dry Eye & Moderate Dry Eye & Severe Dry Eye \\
\hline 200 & 150 & 85 \\
\hline
\end{tabular}




\section{Severity of Dry Eye}

85

150

- Patients having mild dry eye a Patients having moderate dry eye

- Patients having severe dry eye

Chart-7: Severity of Dry Eye

Table-8: Profile of Patients

\begin{tabular}{|c|c|c|c|}
\hline \multicolumn{4}{|l|}{ Patient Characteristics } \\
\hline & Male & Female & Total \\
\hline $\begin{array}{l}\text { Daily time spent on screen }(>20 \mathrm{~h} / \text { day }) \\
\text { Television } \\
\text { Computer } \\
\text { Smart Phone }\end{array}$ & 300 & 400 & 700 \\
\hline Smoking Habits & 20 & Nil & 20 \\
\hline \multicolumn{4}{|l|}{ Ocular History and Examination } \\
\hline Cataract Extraction & 25 & 30 & 55 \\
\hline Glaucoma Surgery & 5 & 8 & 13 \\
\hline Ocular Allergy & 50 & 45 & 95 \\
\hline Pterygium & 10 & 25 & 35 \\
\hline Contact Lens Wearers & 5 & 7 & 12 \\
\hline \multicolumn{4}{|l|}{ Concomitant Oral Medication } \\
\hline B-Blockers & 25 & 35 & 60 \\
\hline Antihistamines & 15 & 19 & 34 \\
\hline \multicolumn{4}{|l|}{ Systemic Diseases } \\
\hline Diabetes & 80 & 90 & 170 \\
\hline Hypertension & 120 & 80 & 200 \\
\hline Rheumatoid Arthritis & 4 & 17 & 21 \\
\hline Thyroid Eye Disease & 2 & 7 & 9 \\
\hline
\end{tabular}

DED symptoms are significantly associated with Meibomian Gland Dysfunction, Previous
Refractive Surgery, Previous Cataract Surgery, Ocular Allergy, Pterygium and Diabetes.

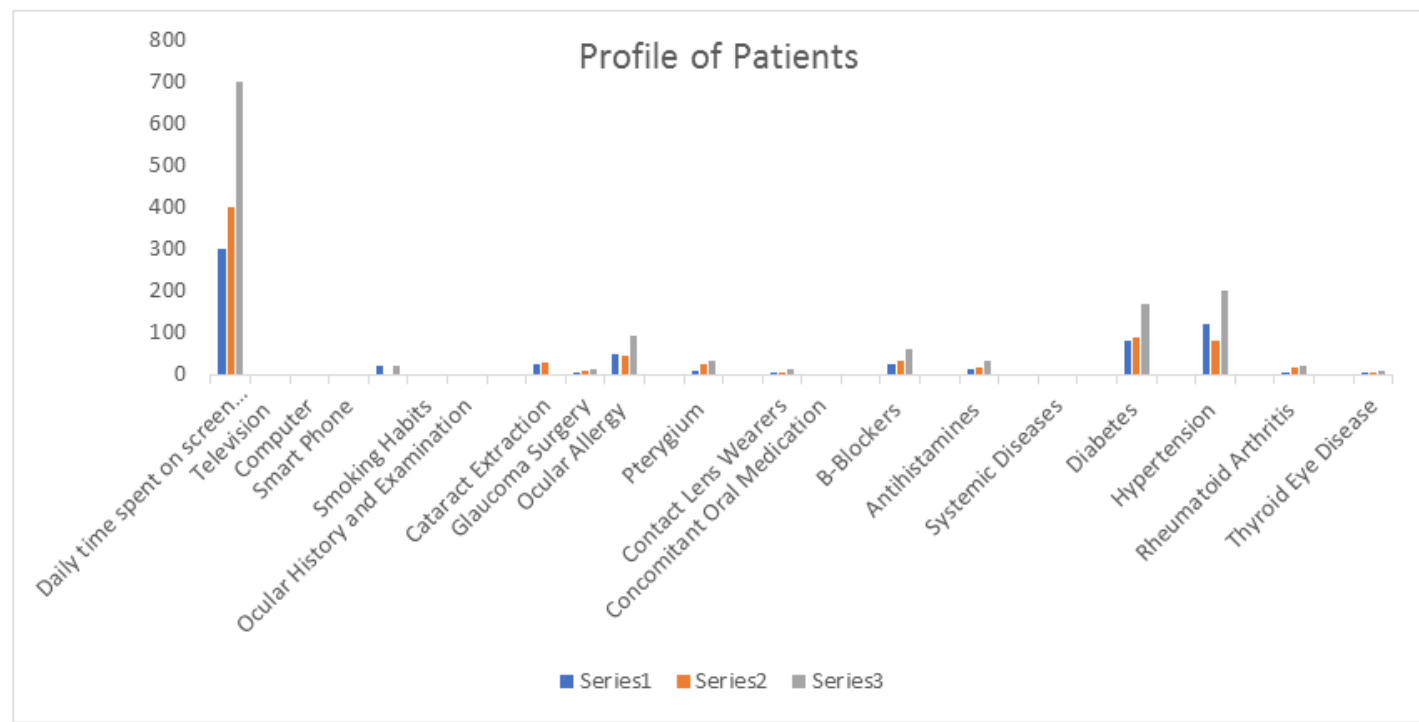

Chart-8: Profile of Patients 
Table-9: Prevalence studies of Dry Eye Disease in Asia

\begin{tabular}{|c|c|c|c|c|c|}
\hline \multicolumn{6}{|c|}{ Prevalence studies of Dry Eye Disease in Asia } \\
\hline References & Country & Sample number & $\begin{array}{l}\text { Age } \\
\text { (years) }\end{array}$ & $\begin{array}{l}\text { Criteria used for } \\
\text { diagnosis }\end{array}$ & Prevelance \\
\hline Lin et al., [7] & $\begin{array}{l}\text { Chinese in } \\
\text { Taiwan }\end{array}$ & 1361 & $\geq 65$ & $>1$ symptom & $\begin{array}{l}33.7 \%(96 \% \text { of } \\
\text { them had } \geq 1 \\
\text { positive test) }\end{array}$ \\
\hline Lam et al., [8] & $\begin{array}{l}\text { China (Hong } \\
\text { Kong) }\end{array}$ & $\begin{array}{l}235 \text { (111 had Schirmer's } \\
\text { test) }\end{array}$ & $>18$ & $\begin{array}{l}\text { OSDI }>55 \text { and } \\
\text { Schirmer's test }<10\end{array}$ & $8 \%$ \\
\hline Nita et al., [9] & India & 237 & $20-80$ & $\begin{array}{l}\text { Schirmer's test and } \\
\text { TBUT }\end{array}$ & $\begin{array}{l}62.8 \% \text { of patients } \\
\text { already with } \\
\text { symptoms }\end{array}$ \\
\hline Gupta et al., [10] & $\begin{array}{l}\text { India (New } \\
\text { Delhi) }\end{array}$ & 400 & $>40$ & $\begin{array}{l}\text { OSDI, McMonnies, } \\
\text { Schirmer's test }\end{array}$ & $\begin{array}{l}29.25 \% \text { and showed } \\
\text { correlation with } \\
\text { Schirmer's test }\end{array}$ \\
\hline Rege et al., [11] & India & $\begin{array}{l}782 / 4750 \text { who scored }>14.5 \\
\text { in McMonnies questionnaire }\end{array}$ & $>18$ & Clinical tests & $15.4 \%$ \\
\hline Lee et al., [12] & Indonesia & 1058 & $\geq 21$ & $\begin{array}{l}\geq 1 \text { of } 6 \text { symptoms } \\
\text { often or all the time }\end{array}$ & $27.5 \%$ \\
\hline Shimmura et al., [13] & Japan & 2500 & $\begin{array}{l}86 \% \text { were } \\
20-49 \\
\text { years }\end{array}$ & $\begin{array}{l}\text { Self-diagnosis } \\
\text { questionnaire }\end{array}$ & $33 \%$ \\
\hline
\end{tabular}

\section{DISCUSSION}

Dry eye is a far too common disorder seen in ophthalmic practice, presenting with myriad of symptoms and signs that the clinician too often overlooks, resulting in under diagnosis of the condition. In this study, an attempt was made to find out the magnitude of the problem in patients visiting Drishti the Vision Eye Hospital Indore, their Sex, Age Distribution, and their common Symptomatology.

DED is one of the most prevalent ophthalmic disorders and may have an adverse impact on the quality of life. In addition to causing various disabling symptoms, it may also compromise the results of the corneal, cataract, and refractive surgical procedures.

Higher rates were generally observed with studies using clinical criteria only, followed by questionnaire-based studies, with lower rates amongst intention-to-treat or treatment studies.

The prevalence of dry eye in our study based on OSDI Questionnaire, TBUT and Schirmer's Test is $30 \%$. The prevalence of DED in India is higher than the global prevalence and ranges from $18.4 \%$ to $54.3 \%$. The vast disparity in the prevalence of DED may be attributed to endemic geographic variations as well as the use of different diagnostic criteria by various studies. In our study, the majority of patients with DED were in the age group of 20-40 years. Females are affected more commonly than males in a majority of studies. We observed a significantly higher occurrence of DED in males. Since ours was a hospital-based study, this trend could be attributed to the lack of treatment- seeking behavior among females in the developing countries.
Desk job with computer use was significantly associated with the risk of developing severe DED. The low- relative humidity in indoor office environment and air- conditioned rooms negatively impacts the tear film by causing desiccation of the eye. We observed a strong association between VDT usage and severe DED. Computer use for more than $8 \mathrm{~h}$ a day has been reported as a significant risk factor for DED, mainly attributed to the decrease in blink rate while using these devices, thereby hampering the uniform distribution of the tear film over the ocular surface. Increasing use of computers, laptops, tablets, smartphones and television has led to an increase in the prevalence of DED in the younger population.

We observed a significant association of DED with contact lens usage as well as smoking. Contact lens usage may cause Dry Eye or aggravate preexisting DED. Nearly $50 \%$ of contact lens users may complain of symptoms of dryness, discomfort, grittiness, irritation, burning, or foreign body sensation. Smoking may affect the tear film stability as well as ocular surface sensitivity, and a significant association has been reported between smoking and DED.

The poor correlation between symptoms and signs has been frequently reported in the literature. In this study, the strong association between positive TBUT and significant Dry Eye symptoms was found. We found a good association between Subjective Symptoms and Signs of Dry Eye.

\section{Conclusions}

We observed the prevalence of DED in Central India to be $30 \%$, with the age group of $20-40$ years affected most commonly. VDT use, smoking, and contact lens use were associated with increased risk of developing DED. 


\section{REFERENCES}

1. Lemp MA. Report of the national eye institute/industry workshop on clinical trials in dry eyes. CLAO Journal, 1995;21(4):221-32.

2. Definition DE. The definition and classification of dry eye disease: report of the Definition and Classification Subcommittee of the International Dry Eye Workshop. Ocul Surf. 2007;5:75-92.

3. Craig JP, Nichols KK, Akpek EK, Caffery B, Dua HS, Joo CK, Liu Z, Nelson JD, Nichols JJ, Tsubota K, Stapleton F. TFOS DEWS II definition and classification report. The ocular surface. 2017 Jul 1;15(3):276-83.

4. Kallarackal GU, Ansari EA, Amos N, Martin JC, Lane C, Camilleri JP. A comparative study to assess the clinical use of Fluorescein Meniscus Time (FMT) with Tear Break up Time (TBUT) and Schirmer's tests (ST) in the diagnosis of dry eyes. Eye. 2002 Sep;16(5):594-600.

5. Schiffman RM, Christianson MD, Jacobsen G, Hirsch JD, Reis BL. Reliability and validity of the Ocular Surface Disease Index. Arch Ophthalmol, 2000; 118:615-621.

6. Bron AJ, Evans VE, Smith JA. Grading of corneal and conjunctival staining in the context of other dry eye tests. Cornea 2003; 22:640-650.
7. Lin PY, Tsai SY, Cheng CY, Liu JH, Chou P, Hsu WM. Prevalence of dry eye among an elderly Chinese population in Taiwan: the Shihpai Eye Study. Ophthalmology, 2003; 110:1096-1101.

8. Lam DKT, Wong VWY, Chow VWS, Chi SCC. Epidemiology of dry eye syndrome in Hong Kong: a cross-sectional population-based study. Hong Kong Journal Ophthalmol, 2011; 15:58-62.

9. Nita S, Verghese A, Joseph V. Dry eye - a hospital based incidence study.Kerala J Ophthalmol, 2009; 21:396-401.

10. Gupta N, Prasad I, Jain R, D’Souza P. Estimating the prevalence of dry eye among Indian patients attending a tertiary ophthalmology clinic. Ann Trop Med Parasitol, 2010; 104:247-255.

11. Rege A, Kulkarni V, Puthran N, Khandgave T. A clinical study of subtype based prevalence of dry eye. Journal Clin Diagn Res, 2013; 7:2207-2210.

12. Lee AJ, Lee J, Saw SM, Gazzard G, Koh D, Widjaja D, Tan DT. Prevalence and risk factors associated with dry eye symptoms: a population based study in Indonesia. Br J Ophthalmol, 2002; 86:1347-1351

13. Shimmura S, Shimazaki J, Tsubota K. Results of a population-based questionnaire on the symptoms and lifestyles associated with dry eye. Cornea, 1999;18:408-411. 